\title{
Diagnóstico por la imagen de los trastornos de la articulación craneomandibular
}

\author{
López López J*, Chimenos Küstner E*, Blanco Carrión A** \\ Reselló Llabrés $\mathrm{X}^{* * *}$, Jané Salass $\mathrm{E}$
}

\section{RESUIMEN}

El diagnóstico de las alteraciones que afectan a la articulación craneomandibular (ACM) debe basarse en la información obtenida a través de la anamnesis médica, de la exploración física y de los factores psiocoemocionales presentes en el paciente. También es importante constatar los síntomas dolorosos y disfuncionales presentes, así como los problemas auditivos, del habla y de la deglución entre otros que le puedan aquejar. La valoración integral del complejo articular debe incluir los tejidos orofaciales, la función muscular y neurológica, el estudio de la oclusión y de los movimientos mandibulares y la identificación de los posibles hábitos parafuncionales.

Si bien todo lo anterior es imprescindible en muchas ocasiones debemos apoyarnos en las diferentes técnicas de diagnóstico por la imagen para poder etiquetar el cuadro clínico que aqueja al paciente.

En el presenta trabajo revisamos y actulizamos los conceptos referentes al diagnóstico por la imagen de los trastornos que afectan a esta articulación.

Palabras claves: Articulación temporomandibular / Articulación craneomandibular / Diagnóstico radiológico

\section{ABSTRACT}

Clinical history, exploration and anamnesis about depressive -anxious symptoms are the basis of diagnosis of temporomandibular disorders. It's also very important to know about pain, loss of function of temporomandibular joint, swallowing and talking. We should consider temporomandibular joint as a syndrome and is necessary to include an exploration of orofacial tissues, muscles, nerves and parafunctions.

After the anamnesis and exploration, it's necessary to perform some test, mainly based in imaging techniques, in order to reach a correct diagnosis.

In this paper we review the importance of imaging in the diagnosis of temporomandibular disorders.

Key words: Temporomandibular joint / Craneomandibular joint / Radiodiagnosis

Aceptado para publicación: Julio 2004.

* Profesor Titular de Medicina Bucal. Facultad de Odontología. Universidad de Barcelona.

** Profesor Titular de Medicina Bucal. Facultad de Odontología y Medicina. Universidad de Santiago de Compostela.

*** Profesor Asociado de Medicina Bucal. Facultad de Odontología. Universidad de Barcelona.

López López J, Chimenos Küstner E, Blanco Carrión A, Reselló Llabrés X, Jané Salas E. Diagnóstico por la imagen de los trastornos de la articulación craneomandibular. Av. Odontoestomatol 2005; 21-2: 71-88. 


\section{INTRODUCCIÓN}

El diagnóstico de las alteraciones que afectan a la articulación craneomandibular (ACM) debe basarse en la información obtenida a través de la anamnesis médica, de la exploración física y de los factores psiocoemocionales presentes en el paciente. También es importante constatar los síntomas dolorosos y disfuncionales presentes, así como los problemas auditivos, del habla y de la deglución entre otros que le puedan aquejar. La valoración integral del complejo articular debe incluir los tejidos orofaciales, la función muscular y neurológica, el estudio de la oclusión y de los movimientos mandibulares y la identificación de los posibles hábitos parafuncionales (1).

Si bien las técnicas de diagnóstico por la imagen han mejorado considerablemente en los últimos años, sólo cuando tengamos constatados todos los elementos previos, $y$, en definitiva, tengamos una presunción diagnóstica. Es decir sepamos lo que queremos encontrar o descartar, es lógico que recurramos a ellas. A la radiografía simple y tomografía clásica se añaden los ortopantomografos modernos que permiten obtener mejores imágenes de la articulación en sentido anteroposterior y transversal. La Tomografía Computarizada (TC) es la prueba complementaria que mejor identifica los tejidos duros o elementos óseos, mientras que la Resonancia Magnética (RM) se describe como la prueba de referencia para valorar tejidos blandos (músculos, ligamentos, menisco), tanto en posición estática como dinámica. Tampoco hemos de desdeñar la valiosa aportación que nos ofrece la reconstrucción tridimensional, los modelos de espuma de poliuretano y esterolitografía y en menor grado la escintigrafia, así como otros métodos diagnósticos $(2,3)$.

Estas pruebas pueden ayudar a confirmar o poner en duda el diagnóstico previo establecido. No hemos de olvidar que los exámenes complementarios permiten obtener información adicional pero no deben servir para establecer el diagnóstico. Sólo deberíamos solicitarlos cuando la información aportada nos influya en el plan terapéutico $(1,4)$. Existen además algunos aspectos que complican el diagnóstico por la imagen de la articulación temporomandibular (3):
- El cóndilo y la fosa presentan gran variedad anatómica.

- Las técnicas que informan bien acerca de los tejidos duros no son las ideales para los tejidos blandos y viceversa.

- Un gran número de estructuras óseas colindantes pueden superponerse en la imagen obtenida.

- La propia situación tridimensional del cóndilo en la fosa puede producir imágenes distorsionadas y eso obligaría a individualizar el ángulo de proyección en cada individuo.

\section{PATOLOGÍA DE LA ARTICULACIÓN CRANEOMANDIBULAR}

\section{TABLA 1.- CLASIFICACIÓN DE LOS DESÓRDENES DE LA ARTICULACIÓN TEMPOROMANDIBUILAR SEGÚIN BERMEJO A.(5)}

\section{MIOPATÍAS}

- Desórdenes funcionales (dolor miofascial):

- Dolor miofascial de cabeza y cuello.

- Hiperactividad muscular masticatoria.

- Mioespasmo.

- Rigidez refleja o rigidez muscular protectora.

- Desórdenes traumáticos: desgarros y rotura.

- Desórdenes inflamatorios:

- Miositis por sobreuso muscular intermitente.

- Miositis generalizada por infección.

- Desórdenes degenerativos, endocrinos, metabólicos y tóxicos:

- Contractura miofibrótica o trismus crónico.

- Distrofias.

- Miastenías.

- Desórdenes del desarrollo:s

- Anormogénesis: malformaciones y malfunciones.

- Hiper e hipoplasias.

- Neoplasias benignas o malignas.

\section{ARTROPATÍAS}

- Luxaciones.

- Desórdenes traumáticos.

- Desórdenes inflamatorios y anquilosantes.

- Desórdenes degenerativos.

- Desórdenes del desarrollo. 


\section{TABLA 2.- CLASIFICACIÓN DE LOS DESÓRDENES DE LA ARTICULACIÓN TEMPOROMANDIBULAR EN BASE A LOS CRITERIOS DE LA AAOP (7). TODOS LOS TRASTORNOS SE ENCUENTRAN DENTRO DE LA CATEGORÍA 11 QUE INCLUYE (EN CURSIVA) OTRAS ALTERACIONES}

\begin{tabular}{|c|c|}
\hline 11.1 Huesos craneales & $\begin{array}{l}\text { 11.1.1. Desórdenes congénitos y del desarrollo } \\
\text { 11.1.1.1. Aplasia } \\
\text { 11.1.1.2. Hipoplasia } \\
\text { 11.1.1.3. Hiperplasia } \\
\text { 11.1.1.4. Displasia } \\
\text { 11.1.2. Desórdenes adquiridos } \\
\text { 11.1.2.1. Neoplasias } \\
\text { 11.1.2.2. Fracturas }\end{array}$ \\
\hline \multicolumn{2}{|l|}{ 11.2. Cuello } \\
\hline \multicolumn{2}{|l|}{ 11.3. Ojos } \\
\hline \multicolumn{2}{|l|}{ 11.4. Oídos } \\
\hline \multicolumn{2}{|l|}{ 11.5. Nariz y senos } \\
\hline \multicolumn{2}{|l|}{ 11.6. Dientes y estructuras relacionadas } \\
\hline 11.7. ATM & $\begin{array}{ll}\text { 11.7.1. Desórdenes congénitos o de desarrollo } \\
\text { 11.7.1.1. Aplasia } \\
\text { 11.7.1.2. Hipoplasia } \\
\text { 11.7.1.3. Hiperplasia } \\
\text { 11.7.1.4. Neoplasia } \\
\text { 11.7.2. } \\
\text { Desórdenes de transtornos del disco } \\
\text { 11.7.2.1. Desplazamiento con reducción } \\
\text { 11.7.2.2. Desplazamiento sin reducción } \\
\text { 11.7.3. Dislocación de la ATM } \\
\text { 11.7.4. Desórdenes inflamatorios } \\
\text { 11.7.4.1. Capsulitas / Sinovitis } \\
\text { 11.7.4.2. Poliartritismo } \\
\text { 11.7.5. Osteoartrosis (no inflamatorios) } \\
\text { 11.7.5.1. Osteoartritis primaria } \\
\text { 11.7.5.2. Osteoartritis secundaria } \\
\text { 11.7.6. Anquilosis } \\
\text { 11.7.7. Fractura del proceso condilar }\end{array}$ \\
\hline 11.8. Músculos de la masificación & $\begin{array}{l}\text { 11.8.1. Dolor miofascial } \\
\text { 11.8.2. Miositis } \\
\text { 11.8.3. Mioespasmo } \\
\text { 11.8.4. Mialgia local no clasificada } \\
\text { 11.8.5. Contractura miofibrótica } \\
\text { 11.8.6. Neoplasias }\end{array}$ \\
\hline
\end{tabular}

Los trastornos temporomandibulares (TTM) son a criterio de la Academia Americana de Dolor Orofacial (AAOP) un término complejo que abarca diferentes problemas clínicos que afectan a la musculatura masticatoria, a las articulaciones temporormandibulares (ATM) y a las estructuras asociadas. Por su parte Bermejo las cataloga de enfermedades orgánicas o funcionales que afectan al sistema de relación craneomandibular y las clasifica en articulares y musculares.(2,5-7).

Dado que el objeto de este capítulo no es describir los criterios de cada una de las entidades que se presentan dentro del conjunto de desórdenes temporomandibulares, nos limitaremos a presentar en la Tabla 1 y 2 la clasificación aceptada por la Bermejo 


\section{TABLA 3.- CRITERIOS CLÍNICOS EN EL DIAGNÓSTICO DE LOS TRASTORNOS DE LA ATM}

\begin{tabular}{|c|c|}
\hline $\begin{array}{l}\text { Mialgia tipo I } \\
\text { (Sintomatología leve en la } \\
\text { musculatura masticatoria) }\end{array}$ & $\begin{array}{l}\text { - El paciente señala dolor orofacial } \\
\text { - Palpación dolorosa en dos o más zonas musculares }{ }^{1} \text {. El dolor } \\
\text { ha de ser de } 2 \text { o más en una escala de } 0 \text { a } 3 \text { en no más de una única localización muscular. }\end{array}$ \\
\hline $\begin{array}{l}\text { Mialgia tipo II } \\
\text { (Sintomatología moderada / } \\
\text { intensa en la musculatura } \\
\end{array}$ & $\begin{array}{l}\text { - El paciente señala dolor orofacial } \\
\text { - Palpación dolorosa en dos o más zonas musculares }{ }^{1} \text {. El dolor ha de ser en } 2 \text { o más zonas } \\
\text { clasificado como } 2 \text { en una escala de } 0 \text { a } 3 \text {. }\end{array}$ \\
\hline $\begin{array}{l}\text { Disfunción dolorosa miofacial } \\
\text { (Dolor muscular con disfunción } \\
\text { muscular) }\end{array}$ & $\begin{array}{l}\text { - Mialgia tipo I o II } \\
\text { - Apertura mandibular no asistida }<\text { a } 40 \text { mm y apertura mandibular asistida > a } 4 \text { mm o más } \\
\text { con relación a la no asistida }\end{array}$ \\
\hline $\begin{array}{l}\text { Alteración interna tipo I } \\
\text { (Luxación del disco con reducción) }\end{array}$ & $\begin{array}{l}\text { - Chasquido en la ATM durante el movimiento mandibular } \\
\text { - Chasquido en la ATM durante el movimiento lateral o de protusión } \\
\text { - Cierre normal con o sin chasquido }\end{array}$ \\
\hline $\begin{array}{l}\text { Alteración interna tipo II } \\
\text { (Luxación del disco con } \\
\text { reducción y bloqueo episódico) }\end{array}$ & - Igual que el anterior pero son períodos breves de bloqueo durante la apertura \\
\hline $\begin{array}{l}\text { Alteración interna tipo III } \\
\text { (Luxación del disco sin } \\
\text { reduccion) }\end{array}$ & $\begin{array}{l}\text { - Apertura mandibular no asistida < a } 35 \mathrm{~mm} \\
\text { - Apertura mandibular asistida > en } 3 \mathrm{~mm} \text { o menos con respecto a la no asistida } \\
\text { - Antecedentes de reducción súbita durante la apertura } \\
\text { - Cuando existen antecedentes de chasquido deben coincidir la desaparición del chasquido y la } \\
\text { disminución súbida en la apertura }\end{array}$ \\
\hline Capsulitis / Sinovitis & $\begin{array}{l}\text { - Dolor en la articulación durante la palpación } \\
\text { - Dolor en la articulación durante la función } \\
\text { - Dolor en la articulación durante la apertura asistida } \\
\end{array}$ \\
\hline $\begin{array}{l}\text { Sobrecarga / esguince por } \\
\text { traumatismo }\end{array}$ & $\begin{array}{l}\text { - Igual que la capsulitis más: } \\
\text { - Antecedentes de traumatismo reciente antes de la aparición del dolor } \\
\text { - Dolor en los movimientos hacia derecha o izquierda o bien dolor en los movimientos de } \\
\text { protusión o retroversión }\end{array}$ \\
\hline $\begin{array}{l}\text { Perforación del ligamento / } \\
\text { disco posterior }\end{array}$ & - Sin criterios clínicos distintivos \\
\hline $\begin{array}{l}\text { Enfermedad articular } \\
\text { degenerativa (artritis / artrosis con } \\
\text { artralgias }\end{array}$ & $\begin{array}{l}\text { - Igual que en la capsulitis más ausencia de positiividad en pruebas analícas para las } \\
\text { enfermedades del colágeno vascular } \\
\text { - Puede ser necesario la presencia de crepitación para establecer el diagnóstico clínico de } \\
\text { enfermedad articular degenerativa }\end{array}$ \\
\hline $\begin{array}{l}\text { Enfermedad articular degenerativa } \\
\text { (artritis / artrosis) sin artralgias, } \\
\text { del envejecimiento, traumática, } \\
\text { idiopática }\end{array}$ & $\begin{array}{l}\text { - Igual que la enfermedad articular degenerativa con artralgias, excepto por la ausencia de dolor } \\
\text { en la articulación durante la palpación, la función o el movimiento }\end{array}$ \\
\hline $\begin{array}{l}\text { Enfermedad sistémicas de } \\
\text { colágeno vascular, con afectación } \\
\text { local }\end{array}$ & $\begin{array}{l}\text { - Igual que la capsulitis más. } \\
\text { Positividad en pruebas analíticas para enfermedades del sistema inmunitario o bien presencia de } \\
\text { los criterios clínicos necesarios para el diagnóstico de enfermedad del colágeno. }\end{array}$ \\
\hline
\end{tabular}

y la $A A O P$ respectivamente $(5,7)$. De igual manera en la Tabla 3, exponemos los criterios clínicos de diagnóstico desarrollados por Trueleve en 1992 (8).

En base a los trastornos que en las tablas se describen cuando estudiamos la articulación con métodos diagnósticos complementarios nuestro objetivo es obtener información acerca de los tejidos duros, blandos o ambos. Por otro lado y para que nos sirva de referencia en la Tabla $4(2,9,10)$ se muestra la eficacia comparativa de los diferentes exámenes de que disponemos en la actualidad. Exámenes que describiremos a continuación.

\section{RADIOLOGÍA CONVENCIONAL}

Las técnicas radiográficas clásicas se ven dificultadas 


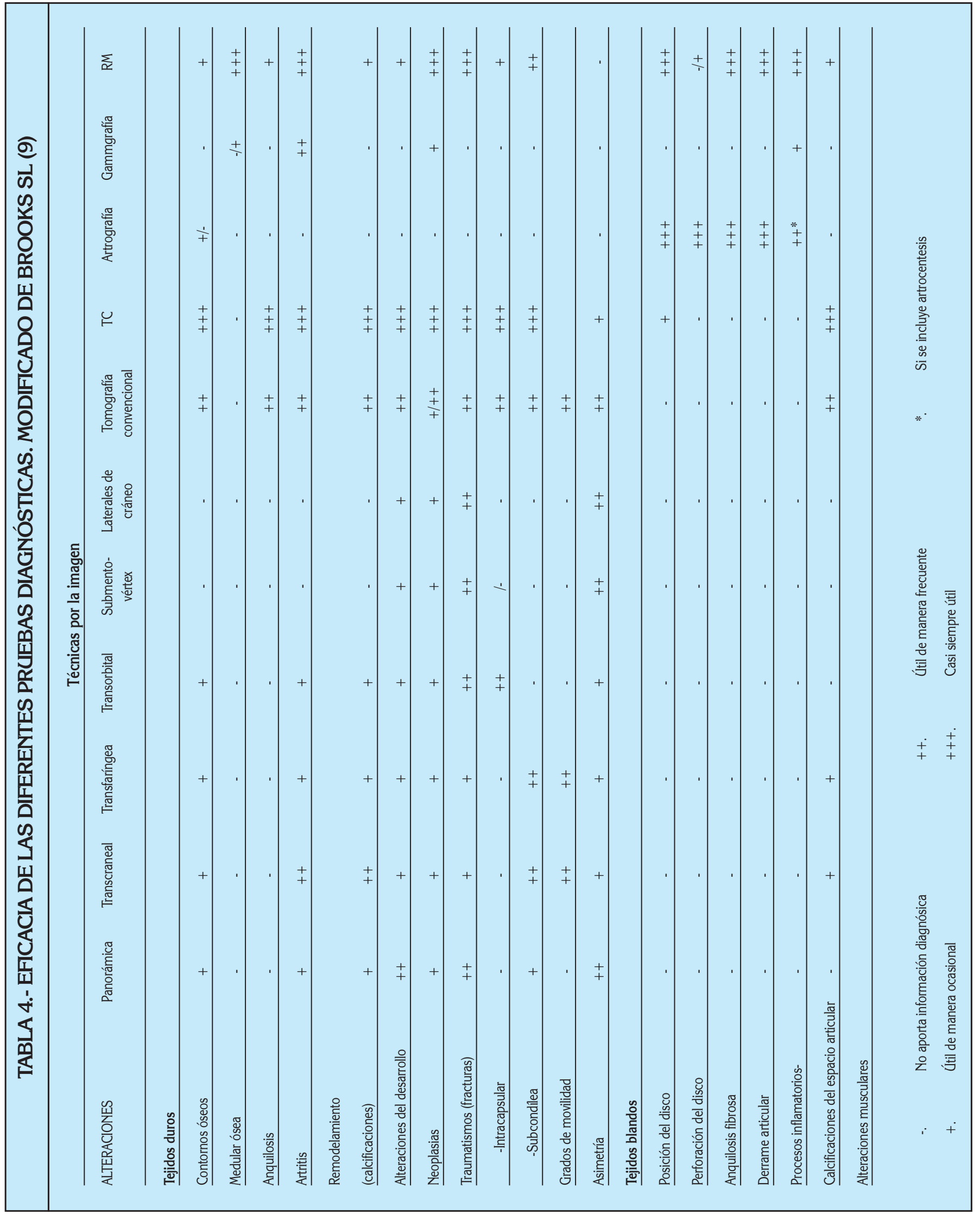




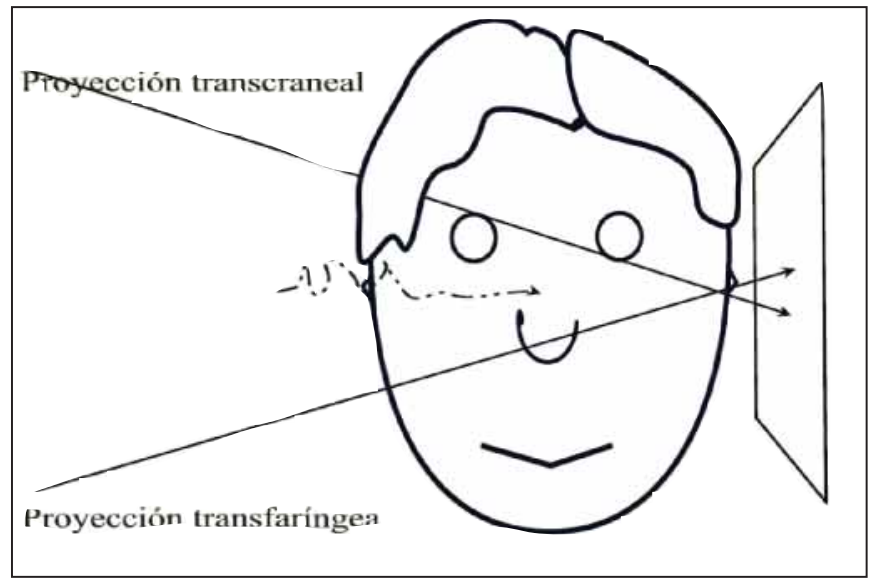

Fig. 1. La proyección lateral pura se ve dificultada por la superposición de estructuras. Podemos solventar parcialmente el problema realizando proyecciones oblícuas, una superior o transcraneal y una inferior (transfaríngea o infracraneal). Basado en Okesson J. (Modificado).

por las características anatómicas de la zona. Una proyección de perfil pura es imposible por la super- posición de las estructuras de la cara. En base a ello para mejorar los resultados los rayos deben dirigirse desde debajo (infracraneal o transfaríngea) o atravesando el cráneo (transcraneal). De esta manera podemos obtener imágenes de perfil de la zona que nos permitirán analizar los tejidos duros, la relación entre el cóndilo y fosa, así como el grado de movilidad (Figura 1).

De las diferentes técnicas radiográficas que nos ayudan al diagnóstico: proyección panorámica (infracraneal), proyección transfaríngea (infracraneal), proyección transcraneal lateral, proyección transmaxilar anteroposterior (AP) y otras; son la ortopantomografía y la transcraneal lateral oblícua las que todavía, y con muchas reservas, en la actualidad podrían tener alguna indicación dentro de la patología de la ATM (Figuras 2, 3, 4). Repasaremos a continuación algunos datos de cada una de ellas.

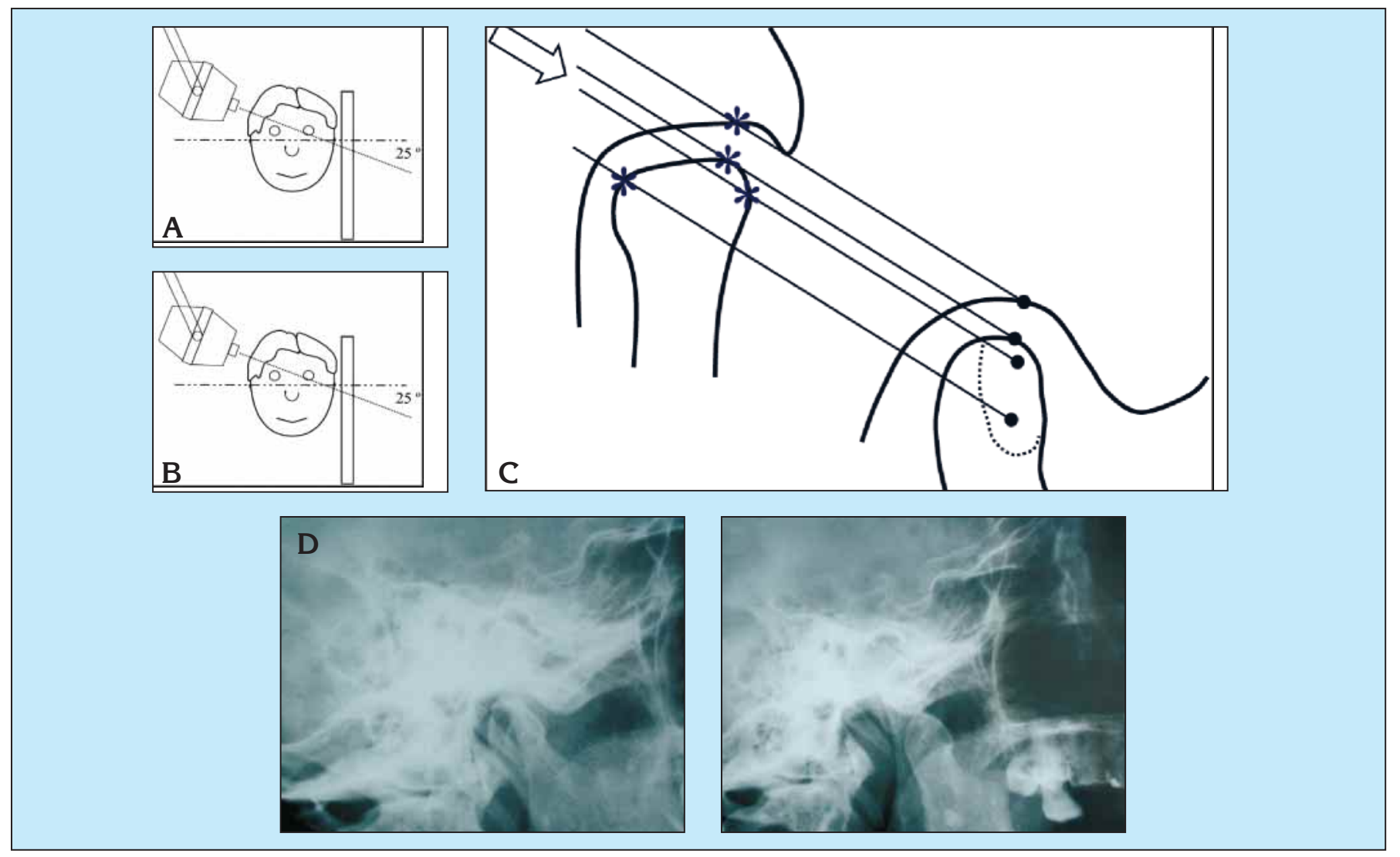

Fig. 2. Proyección transcraneal. (A) El rayo central se orienta en un ángulo de $25^{\circ}$ desde el lado opuesto. En el plano anterior se inclina $20^{\circ}$ (B). El área que parece corresponder a la superficie subarticular superior, corresponde en realidad al polo lateral. El polo medial está superpuesto en la parte inferior sobre el cuello del cóndilo (C). Es decir permite obtener una buena imagen del cóndilo dado que la fosa no se superpone (D). Basado en Okesson J (4) y White S (10) (Modificado). 

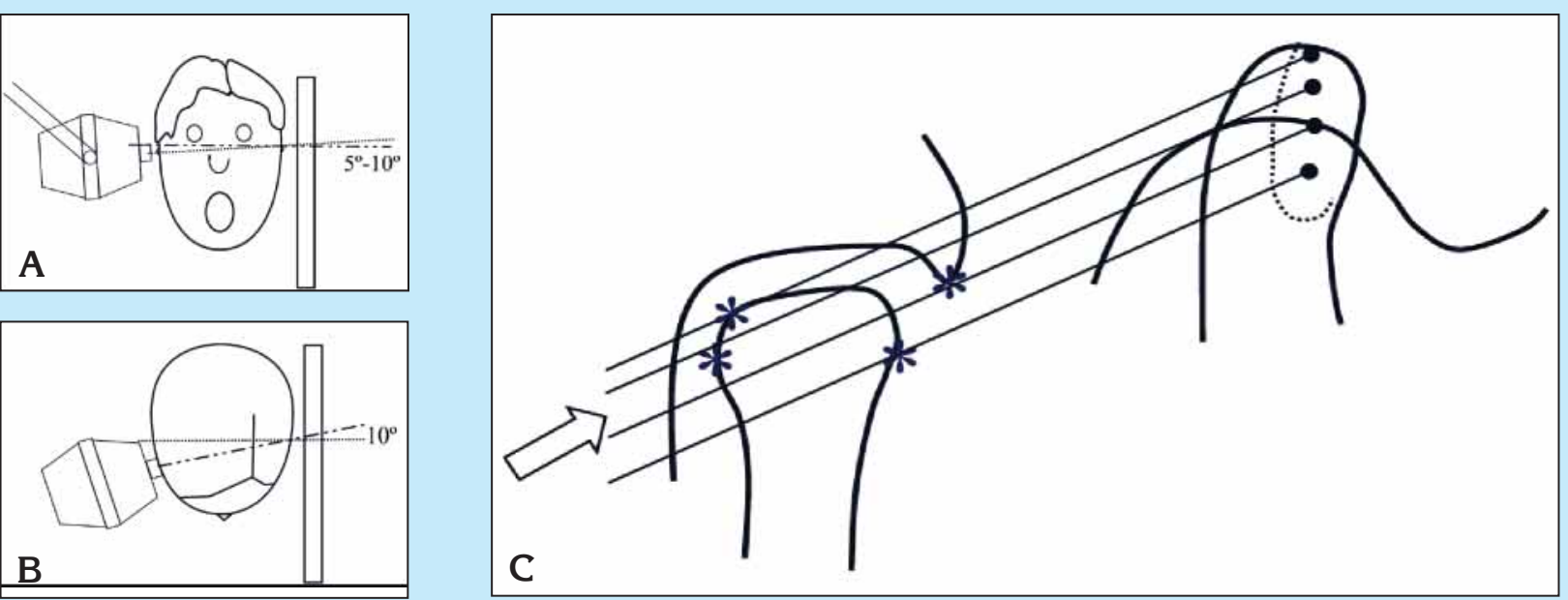

B

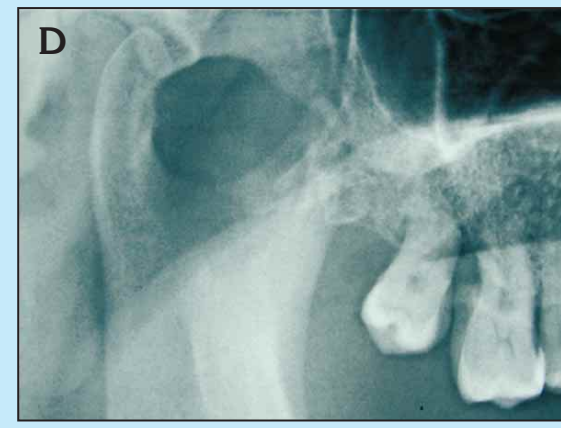

Fig. 3. Proyección transfaríngea. (A) El rayo central se orienta en un plano superior de 5-10 y aproximadamente $10^{\circ}$ en el plano posterior (B). La ortopantomografía es una proyección transfaríngea o intracraneal. En ella el área que parece corresponder a la superficie subarticular del cóndilo es en realidad el polo medial. El polo lateral se encuentra superpuesto en la parte inferior sobre el cuerpo del cóndilo. La fosa también se encuentra superpuesta al cóndilo, todos estos aspectos complican la interpretación radiográfica. En (D) vemos una imagen radiográfica de la ATM derecha. Basado en Okesson J (4) y White S (10) (Modificado).

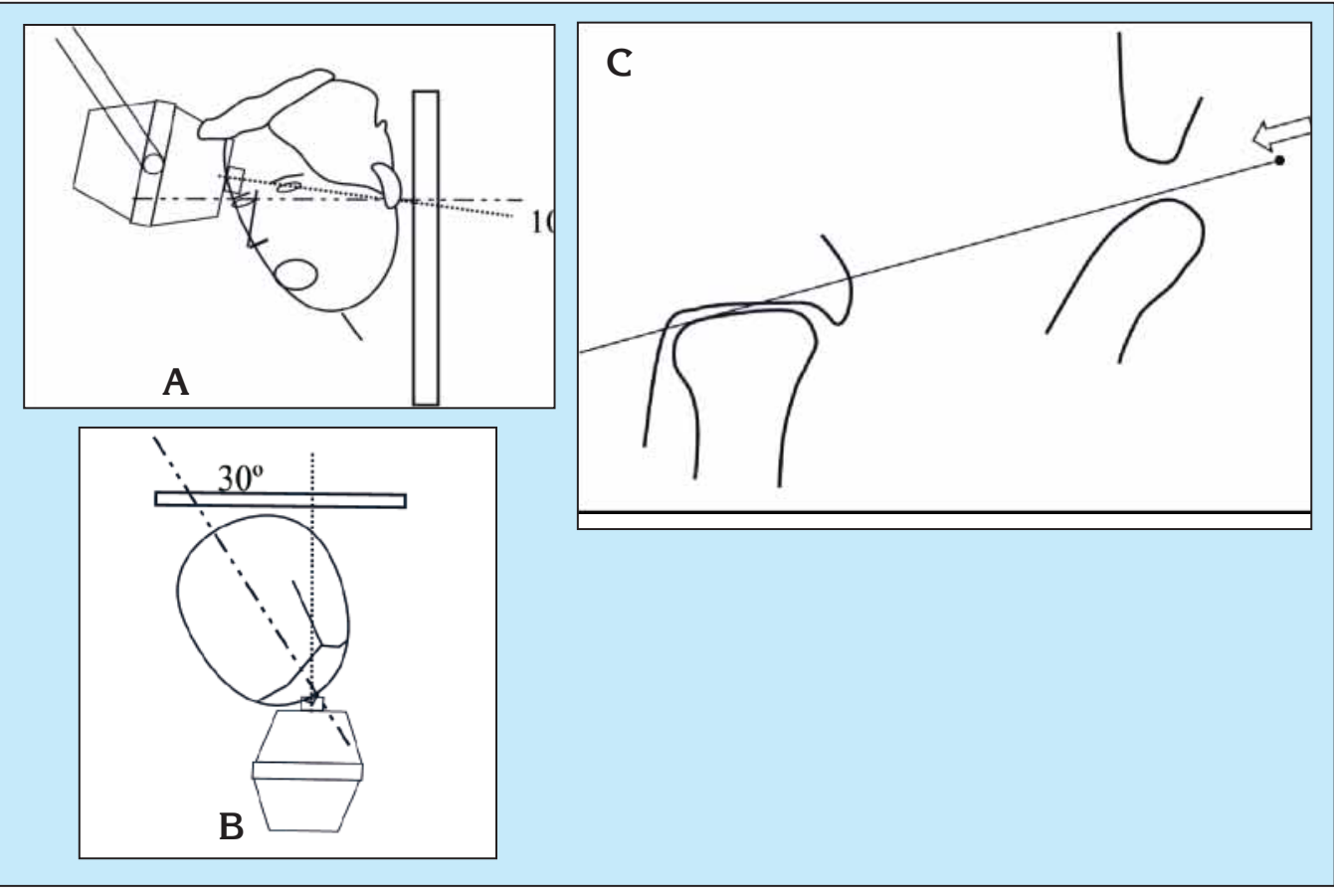

Fig. 4. Proyección transorbital. (A) El rayo se orienta aproximadamente $10^{\circ}$ desde abajo y cerca de $30^{\circ}($ B) a través de la órbita ipsolateral. La proyección anteroposterior o transorbital nos permite ver los polos laterales y medial del cóndilo junto a las superficies subarticulares superiores; pero es frecuente que el proceso mastoideo oscurezca la parte superior articular en la porción medio superior. Basado en Okesson J (4) y White S (10) (Modificado). 


\section{ORTOPANTOMOGRAFÍA (PANORÁMICA)}

En la técnica panorámica rotacional el haz de rayos no atraviesa el eje mayor del cóndilo, se comporta como una imagen oblícua y de proyección transfaríngea (infracraneal). En la actualidad lo correcto sería indicar siempre radiografías digitales ya que no sólo mejora la definición sino que se puede reducir la dosis recibida en un 43\% (11). (Figura 3).

Como ventajas más significativas podemos citar:

- Visión global de dientes, maxilares y de otras estructuras del complejo maxilofacial.

- Algunos aparatos modernos tienen programas especiales para ATM.

- Se pueden apreciar cambios óseos acusados en los cóndilos (asimetrías, erosiones, osteofitos, fracturas).

Sus inconvenientes más relevantes:

- Perspectiva distorsionada y oblícua.

- Engrosamiento de los contornos.

- Mala información sobre la posición y función porque la boca está algo abierta y protuída. En ocasiones para obtener imágenes correctas se ha de abrir la boca al máximo.

- La eminencia se superpone a la base de cráneo y arco zigomático. Sólo se observan bien los cóndilos.

Si tenemos en cuenta que los datos obtenidos en una ortopantomografía pueden coincidir en el 60$70 \%$ de los casos con los que se obtienen en las tomografías (12) y que nos da información valiosa a otros niveles, muchos autores determinan que debería ser la radiografía rutinaria y seguramente única de revisión (9). Pero tampoco hemos de olvidar que en cerca del $90 \%$ de los casos encontraremos lesiones radiográficas en pacientes asintomáticos. En el caso de decidir utilizar este método diagnóstico para el estudio de los elementos articulares, deberemos ser conscientes de los elementos de distorsión (en especial en el palno horizontal) y calcularlos en base a los elementos de asimetría ya establecidos $(13,14)$.

Por otro lado durante tiempo se promulgó la utilidad de las mal denominadas ortopantomografías funcionales (boca abierta y boca cerrada), hoy en día, tendiendo en cuenta que hay pruebas más resolutivas, no está justificado el coste radiológico que representa.

\section{TRANSFARÍNGEA}

Se realiza mediante la técnica descrita por Parma y es parecida a la anterior pero informa de un solo lado. Dado que el ángulo del haz de rayos es menos pronunciado la imagen es más cercana a la realidad. Al igual que la técnica precedente sólo informa bien sobre el cóndilo. Obteniendo una visión sagital del polo medio del cóndilo. Es necesario realizarla en máxima apertura para evitar la superposición del cóndilo con el temporal. Estaría escasamente indicada en la actualidad ya que no aporta ninguna otra información adicional que podamos necesitar.

\section{TRANSCRANEAL (TOC)}

En esta proyección (también denominada trans-oblícua-cráneal, excéntrica transcraneal, o proyección de Schüller) el haz de rayos X se inclina caudalmente para evitar la superposición de la porción petrosa del temporal, también se inclina anteriormente $\left(20^{\circ}\right.$ de forma estándar o personificada mediante una proyección sub-mento-vértex. (Figura 2). Contra más paralelo al eje mayor del cóndilo sea este plano más comportamiento sagital tendrá la imagen obtenida. De forma clásica se analiza en boca abierta y cerrada, y en escasas ocasiones se estudian estadíos intermedios.

Como ventajas podemos destacar:

- Detecta cambios óseos pero sólo si son manifiestos o cuando afectan a la porción lateral (fracturas con desplazamiento y cambios en el grado de movilidad).

- Nos aporta datos, aunque escasos, tanto del cóndilo como de la fosa temporal y resulta de fácil realización, incluso en el gabinete dental.

De entre sus inconvenientes citaremos:

- A veces se superpone al cuello del cóndilo la porción petrosa ipsolateral.

- El cóndilo, el temporal y en especial el espacio articular están distorsionados (sobre todo si el ángulo horizontal no se individualizan para cada paciente). Es necesario valorar ese ángulo para poder interpretarla correctamente.

- Si bien es de utilidad en un proceso artrítico, tanto la RM como la TC aportan más datos e incluso la 
tomografía nos distorsionará menos el cóndilo y el espacio articular apreciable será más fiable.

Así pues, si tenemos en cuenta que está contraindicada para valorar la posición del cóndilo en la fosa, y que la trayectoria condilar se puede determinar clínicamente, son muchos los autores que determinan que en la actualidad no hay ninguna indicación lógica de esta técnica (3).

\section{TRANSORBITAL (ANTEROPOSTERIOR)}

La forma más realizada es en máxima apertura según la técnica de Moffat. Es muy parecida a la transmaxilar. Esta técnica es perpendicular a la proyección transcraneal y transfaríngea. Mediante la apertura o protusión se evita la superposición del temporal o de la base de cráneo. La modalidad POSTEROANTERIOR (proyección inversa de Towne) disminuye considerablemente la irradiación del ojo (Figura 4).

Las ventajas más significativas son:

- Se visualiza la zona mediolateral de la eminencia articular.

- Se visualiza el cuello del cóndilo y la cabeza. Es de utilidad para diagnosticar fracturas (en especial las subcondíleas), con mejor resultado que la tomografía y resultados parecidos a la TC. Puede no resultar significativamente mejor que la ortopantomografía.

- Permite ver la convexidad del cóndilo y analizar el hueso subarticular del mismo.

- En unión a la transfaríngea y transcraneal va bien para valorar anomalías óseas o cambios degenerativos

De entre los inconvenientes se citan:

- Si el cóndilo no puede moverse y llegar a la cresta sólo se verá el cuello y la información obtenida será escasa.

- El contorno superior del cóndilo observado corresponde en realidad a la porción posterosuperior del mismo.

\section{POSTEROAANTERIOR DEL MAXILAR}

Esta proyección modificada según Clementschitsch (proyección craneal occipitofrontal de Clements- chitsch) (3). Se realiza en máxima apertura y nos permite valorar las superficies articulares de los cóndilos (15) , recomendándose hasta hace poco para las fracturas de cuello de cóndilo o intracapsulares. En la actualidad, no obstante, esta superada en calidad diagnóstica por el TC (16). (Figura 4).

\section{PROYECCIÓN SUBMENTOVÉRTEX (SMV, BASAL, DE HIRTZ)}

El haz de rayos es paralelo al borde posterior de la rama ascendente (Figura 5). Nos aporta información sobre los cóndilos, cuello y ramas mandibulares y la base de cráneo. Es de especial utilidad para conocer la angulación del eje mayor de la cabeza del cóndilo que nos permitirá corregir el ángulo en la proyección transcraneal lateral oblícua y de las tomografías sagitales.

De entre las ventajas de esta técnica podemos citar: - Útil, junto a otras, para ver la ATM en el plano lateral.

- Para valorar asimetría facial y desplazamientos condilares. En especial en el plano trasnversal. Permite valorar la rotación mandibular en el plano horizontal tras traumatismos o cirugía ortognática. - Es imprescindible para calcular la inclinación personificada en las tomografías.

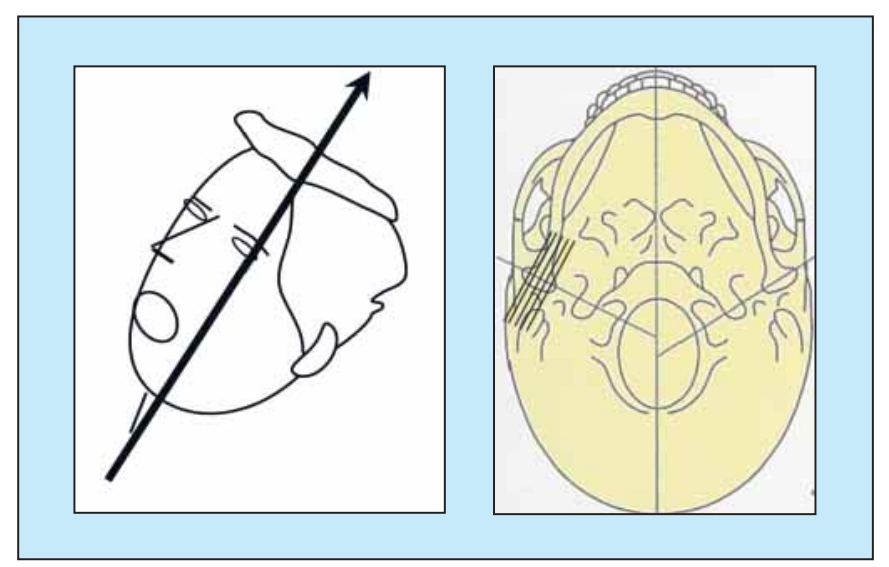

Fig. 5. La proyección sub-mento-vértex permite mostrar ambos cóndilos en proyección axial y calcular por tanto el ángulo adecuado para la realización de la proyección trascraneal o de las tomografías. Modificado de Isberg A (2) y Bumman A (3). 


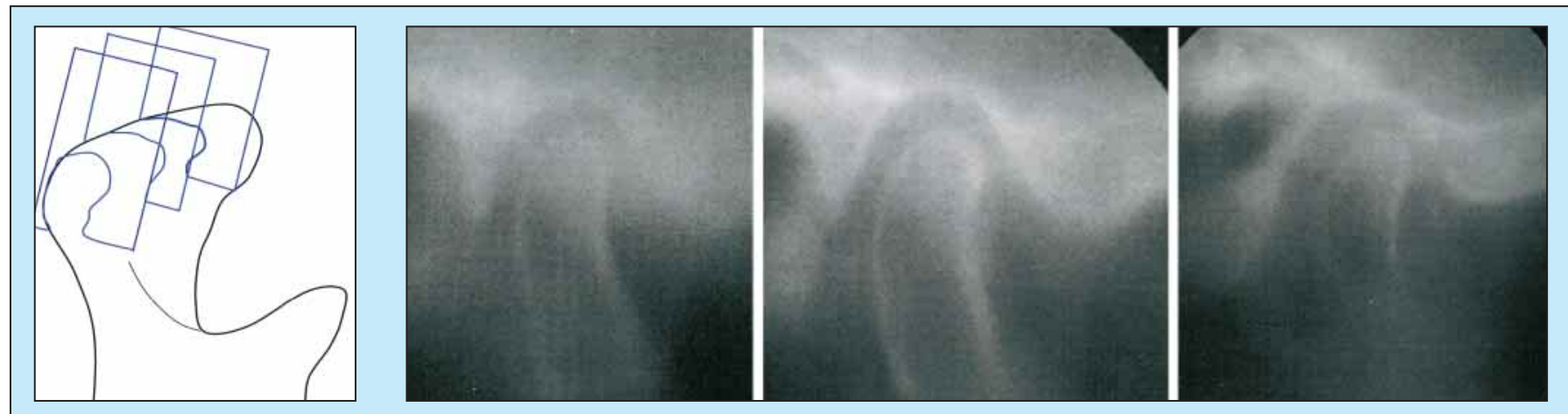

Fig. 6. Se expone una serie de imágenes representando la articulación a diferente nivel de profundidad. Generalmente separadas por distancias de 2 a $4 \mathrm{~mm}$. Modificado y basado en Isberg A (2).

\section{TELERRADIOGRAFÍA FRENTE Y PERFIL}

En especial la técnica de perfil nos permite ver la relación de la ATM (abierta y cerrada), con la columna cervical, base de cráneo, axis y hueso hioides. Son pues útiles para valorar discrepancias secundarias del esqueleto pero no patología intrínseca de la ATM.

\section{TOMOGRAFÍA CONVENCIONAL}

En caso de solicitar una prueba radiológica, aparte de la Orotopantomografía, muchos autores considera que sería la primera a solicitar (4). Se realizan finas secciones para ver las estructuras sin superposiciones (Figura 6)).

Como se pueden obtener diferentes imágenes resulta de más utilidad que la transcraneal para ver la posición del cóndilo o los cambios óseos, y las imágenes obtenidas son auténticas proyecciones laterales.

Mediante el método clásico se presenta en el plano sagital (lateral) con boca cerrada y abierta. Es conveniente la técnica modificada, en ella se utiliza la proyección SMV para obtener el ángulo entre la cabeza y el eje mayor del cóndilo, luego se gira la cabeza en este ángulo, permitiendo un alineamiento de los cortes con el eje mayor del cóndilo. Así se minimiza la distorsión y se localiza mejor la posición del cóndilo. $\mathrm{Si}$ no se puede se hace en un giro aleatorio de $20^{\circ}$. Si se sospechan cambios óseos se pueden hacer tomografías coronales (cortes frontales). Se ha de colocar en máxima apertura o en protusión para evitar superposición.
Entre sus ventajas podemos considerar:

- Mejor identificación de las deformidades y alteraciones óseas ya que ofrece buena imagen de las superficies articulares (en relación con la radiografía convencional pero peor resolución que la TC). La transorbital, no obstante, ofrece mejor información referente a las fracturas.

- Mejor valoración de la posición del cóndilo en la fosa (son proyecciones sagitales verdaderas) y permite una buena exploración de la movilidad, incluso mejor que la RM. Para esta exploración se muestra equivalente a la artrografía y a la proyección trasncraneal de Schüller.

Entre sus desventajas podemos citar:

- Coste.

- Más molestias e irradiación que la radiografía convencional.

- Son de escaso valor para determinar alteraciones óseas incipientes.

Si bien en Estados Unidos están muy consideradas, lo cierto es que muchos autores cuestionan su utilidad $(17,18)$ y tan sólo se podría indicar para valorar la movilidad del cóndilo en la fosa, aspecto que como ya hemos comentado antes, tiene buena valoración clínica.

\section{TOMOGRAFÍA COMPUTARIZADA (TC)}

Las imágenes tomográficas facilitan una información única y valiosa sobre la anatomía, la extensión de las fracturas y los cambios patológicos, en especial para el examen de regiones anatómicamente complejas, 
como la ATM (2). No hemos de olvidar, no obstante, que la técnica en sí ocasiona algunos efectos de distorsión, merece especial atención la sobredimensión que puede ocasionar en las zonas de pequeñas estructuras con muchas curvas, tanto mayor contra más inclinada se encuentre la zona en relación al plano de la imagen (3).

De las dos proyecciones utilizadas, la axial es más fácil de conseguir y resulta ideal para demostrar anomalías óseas, la coronal nos ayuda en el diagnóstico pero es más difícil de conseguir, sobre todo si hay rigidez de cuello. Las imágenes sagitales es posible conseguirlas mediante reformateo de las otras dos proyecciones pero la resolución no es excesivamente buena; algunos aparatos modernos las pueden realizar de forma directa. Desde hace unos años los TC espiroideos consiguen los datos de forma más rápida y precisa y con menor coste de radiación.

Otro aspecto importante a considerar es la posibilidad de una reconstrucción tridimensional del objeto examinado en base a diferentes cortes realizados y mediante la manipulación informática. Este tipo de reconstrucciones están especialmente indicadas de forma prequirúrgica en el tratamiento de hiperplasias e hipoplasias condilares, anquilosis o tumores. $(3,19)$. Algunos autores también recomiendan este tipo de técnica en las fracturas de cuello de cóndilo como medida para valorar la relación exacta del fragmento con la mandíbula. Estos autores preconizan que si el fragmento no tiene contacto con la rama ascendente, en especial en niños y jóvenes, se puede producir un proceso de reabsorción y mediante procesos de reconstrucción se forma un "nuevo" cóndilo (20). La mayor parte de autores, no obstante, recomiendan el uso de la RM por el menor coste en radiación que representa $(21,22)$.

En base a la TC también es posible reconstruir modelos tridimensionales en espuma de poliuretano (una máquina especial de fresado construye el modelo de trabajo en base a los datos que facilita la TC), de esta manera se reducen los tiempos quirúrgicos y el número de intervenciones en las disgnatias y en los síndromes congénitos ya que es posible simular la intervención de forma previa (23). La esterolitografía se empezó a utilizar en los años noventa y es el método de elección si son necesarios detalles óseos y már- genes de cavidades $(23,24)$. En este método además de los datos facilitados por el TC, se emplea un láser que va polimerizando por capas un plástico líquido contenido en un recipiente, de esta manera se consigue el modelo tridimensional $(3,25,26)$.

No hemos de olvidar que a pesar de múltiples modificaciones realizadas y de la posibilidad del efecto ventana, la información obtenida sobre tejidos blandos (disco) es mala. Así pues puede estar indicada para conocer la extensión de las anquilosis, las neoplasias, la afectación ósea en procesos artríticos avanzados, las fracturas complejas y para valorar las complicaciones como las erosiones o el crecimiento ectópico de hueso en la fosa media craneal que se puede originar cuando se emplean implantes en lámina de silicona o de polietrafluoretileno (9). La absorción de radiación del disco nos puede acercar al diagnóstico de hialinización, calcificaciones y metaplasia a dicho nivel.

Si bien su información comparada con las observaciones obtenidas en cadáveres es muy buena para valorar defectos óseos, no debería ser utilizada si la información obtenida no modificará el tratamiento, quedando, por tanto prácticamente relegada a la patología tumoral (10).

Entre sus principales inconvenientes se encuentran: - El coste.

- El tiempo de realización y la exposición elevada de radiación.

- No permite observar el movimiento dinámico de la articulación.

\section{ARTROGRAFÍA}

Nos permite obtener una imagen indirecta del disco mediante la inyección de un contraste radiopaco dentro del compartimento articular superior, inferior o ambos. Se detectará la rotura del disco cuando el contraste pase de un compartimento al otro. Mediante las técnicas fluoroscópicas podemos estudiar la funcionalidad del disco. También resulta de utilidad para determinar adherencias y su única indicación debería ser, y con reservas, la prequirúrgica para tener una buena información de los tejidos blandos $(1,4,10,27)$. 


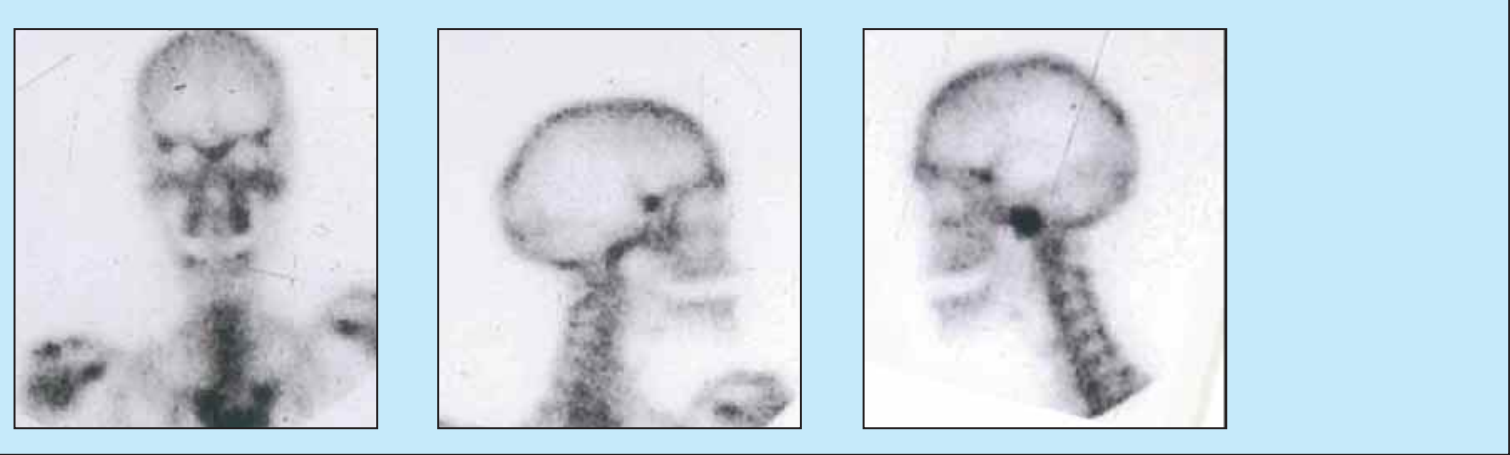

Fig. 7. Se aprecia una captación aumentada en un paciente por poliartritis y afectación específica de la articulación derecha.

Así pues entre sus ventajas podemos citar:

- Ayuda a visualizar tejidos blandos.

- Mediante fluoroscopia se pueden valorar los movimientos discales y del cóndilo.

- Muy útil para las perforaciones discales.

De sus inconvenientes cabe destacar:

- Precisa formación especial.

- Es invasiva, dolorosa y ocasiona una importante irradiación para el paciente.

- Posibilidad de reacciones alérgicas y de infección.

- Incluso una ATM normal puede presentar un cierto desplazamiento anterior del disco debido a la distensión ocasionada por la técnica de las estructuras articulares y a la tracción del pterigoideo lateral superior.

\section{GAMMAGRAFÍA}

Es un método muy sensible al aumento del metabolismo en la zona, es decir a los procesos inflamatorios y tumorales, pero no es específico de estos procesos. No sirve para valorar ni la anatomía ni la biomecánica del disco (2). Figura 7.

\section{ARTROSCOPIA}

Exige una técnica quirúrgica cuidadosa y protocolizada con un cierto nivel de riesgo y que precisa una aparatología específica (28). Permite observar directamente tanto tejidos duros como blandos. En la actualidad debería indicarse sólo cuando otras técnicas no invasivas no nos han aportado datos diagnósticos suficientes. Un elemento a tener en cuenta es que en el acto diagnóstico se puede realizar una biopsia sinovial para detectar cambios histológicos una limpieza terapéutica de la articulación o solucionar fracturas intracapsulares (1,29-31).

\section{RESONANCIA MAGNÉTICA}

La hemos situado al final de esta exposición pero es la técnica de elección para el diagnóstico funcional y patológico de la ATM, no sólo por la información anatómica y funcional que aporta sino porque es una técnica que evita las radiaciones ionizantes $(1,3)$. Es además, la prueba de referencia para identificar posiciones del disco (32). Bermejo le atribuye una especificidad del $96 \%$ y una sensibilidad del $98 \%$ (5). La técnica permite la realización de imágenes sagitales corregidas (que resultan perpendiculares al eje mayor del cóndilo) y coronales sin recolocar al paciente. Los cortes coronales son esenciales para valorar los desplazamientos laterales y medial del disco. La proyección axial, que también se registra, se usa para planificar la estratificación sagital y coronal $(2,3)$.

Mediante el fenómeno de la estratificación de los cortes en el plano axial se pueden realizar angulados o paramediales. Los segundos tienen la ventaja de que presentan menos artefactos procedentes de las arcadas dentales y la posición del cóndilo en boca cerrada y abierta son equivalentes. En el plano coronal los podremos realizar frontales que nos darán información de las dos articulaciones a un tiempo pero que nos ocasionarán errores considerables en la relación disco cóndilo. O bien angulados y paralelos al eje longitudinal del cóndilo que nos corregirá 

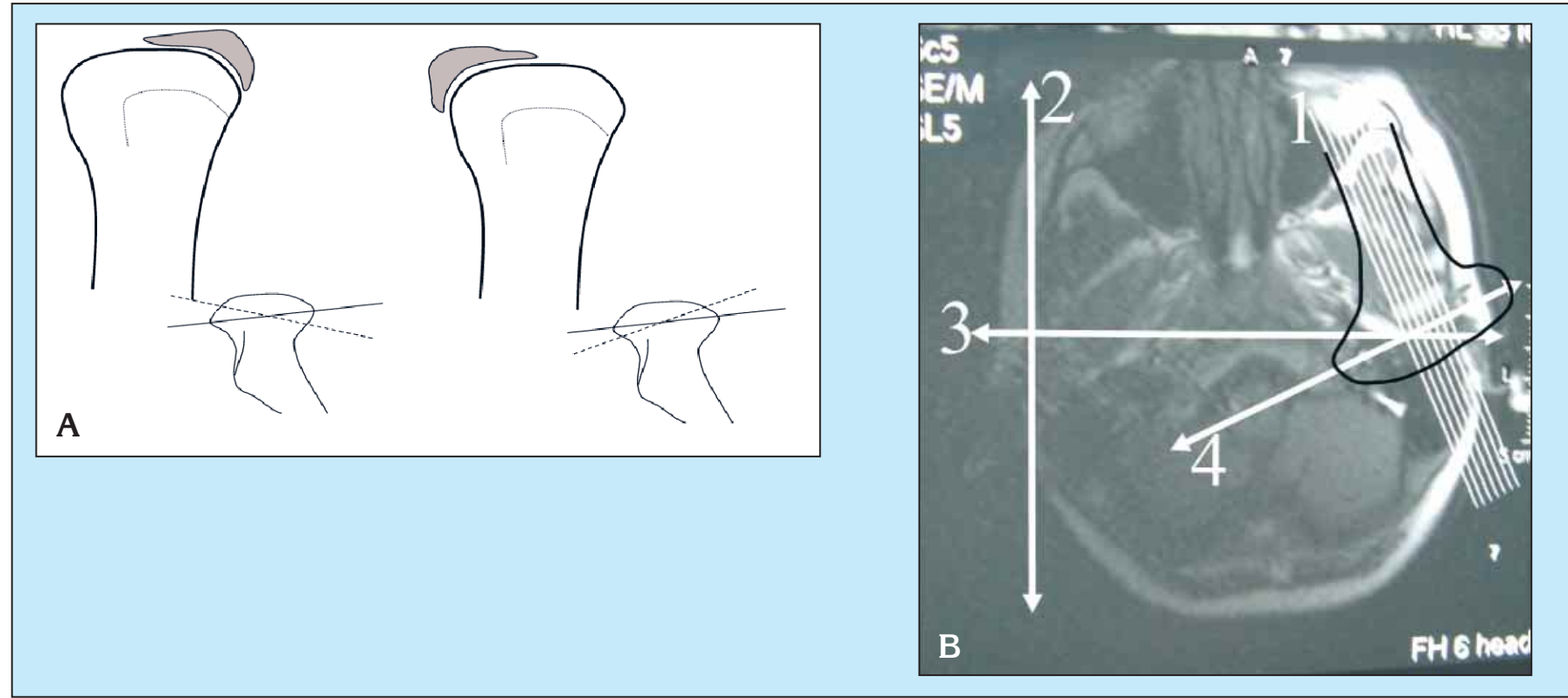

Fig. 8. (A) El eje mayor del cóndilo aparece en línea negra y en línea punteada la línea de angulación. En la izquierda vemos un angulación reducida y la imagen presentará en condiciones normales un desplazamiento medial del disco. En la derecha, con una angulación marcada, la imagen simula un desplazamiento lateral del disco. (B) Los cortes sagitales angulados -1- son los más frecuentemente utilizados, nos permiten obtener la imagen en boca cerrada y abierta equivalente pero se puede ver alterado el resultado por artefactos procedentes de las arcadas dentales. En -2- sería un corte sagital puro no paralelo al eje mayor del cóndilo, en -3- se presenta un corte frontal que permite explorar las dos articulaciones pero no es paralelo el eje mayor del cóndilo; en -4-, por el contrario es un corte frontal paralelo al eje mayor pero obliga a explorar las articulaciones por separado. Modificado de Bumman A (3).
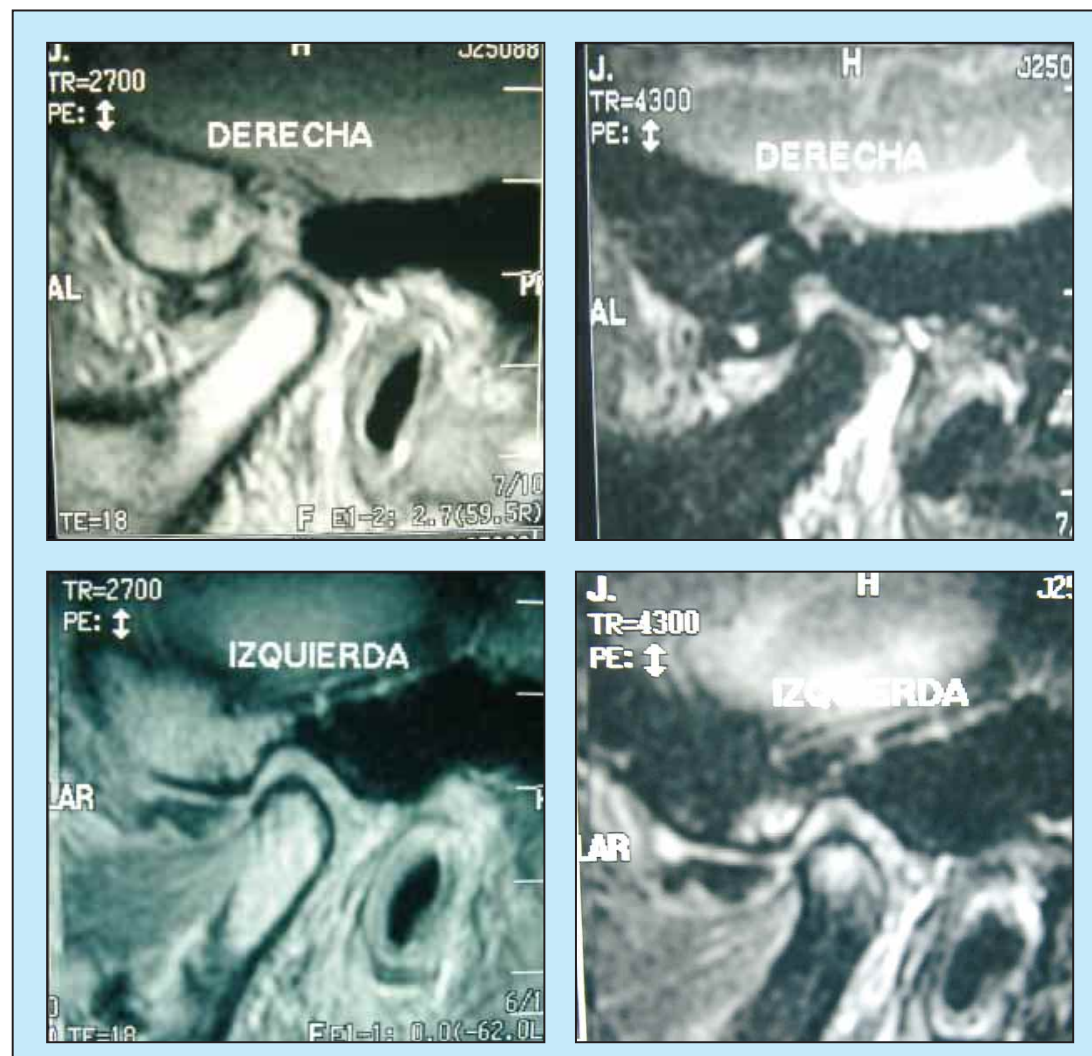

en parte este error y nos explorará ambas articulaciones por separado (3) (Figura 8).

Desde el punto de vista técnico es importante que recordemos que cuanto menor es el valor en T1 de un tejido, mas fuerte es la señal y más clara la imagen obtenida. Si por el contrario el valor en T1 es alto, la imagen será oscura. Los tejidos con un valor alto en T2 dan una señal fuerte y una imagen clara, por el contrario los tejidos con un T2 corto dan una señal débil y una imagen oscura (3). En base a lo anterior las imágenes obtenidas en T1 permiten visualizar los tejidos óseos y el disco, mientras que las imágenes en T2 nos permiten evaluar el grado de inflamación y el derrame articular. (Figura 9). Puede además realizarse de forma dinámica permitiendo valorar la biomecánica del disco y del cóndilo (33). La versatilidad de la técnica permite que el 


\begin{tabular}{|c|c|c|c|c|c|c|c|c|c|c|c|}
\hline TEJIDO & Grasa & $\begin{array}{l}\text { Médula } \\
\text { Osea }\end{array}$ & $\begin{array}{l}\text { Hemosi- } \\
\text { derina } \mathrm{H} \\
\text { (Hemo- } \\
\text { rragia } \\
\text { antigua) }\end{array}$ & $\begin{array}{l}\text { Corteza } \\
\text { cerebral }\end{array}$ & $\begin{array}{c}\text { Substan } \\
\text {-cia } \\
\text { blanca } \\
\text { cerebral }\end{array}$ & $\begin{array}{l}\text { Múscu- } \\
\text { lo sano }\end{array}$ & Disco & $\begin{array}{l}\text { Pseudo- } \\
\text { disco }\end{array}$ & Agua & Cortical & Aire \\
\hline $\begin{array}{l}\text { Densitometría } \\
\text { T1 }\end{array}$ & & & & & & & & & & & \\
\hline $\begin{array}{l}\text { Densitometría } \\
\text { T2 }\end{array}$ & & & & & & & & & & & \\
\hline $\begin{array}{l}\text { Densidad de } \\
\text { protones }\end{array}$ & & & & & & & & & & & \\
\hline
\end{tabular}

Fig. 9. En base a la intensidad de la lesión y la secuencia empleada en la exploración, los diferentes tejidos muestran diferentes tonalidades de gris. Basado en Bumann (3) modificado. Se presenta un desplazamiento sin reducción con un mejor detalle del componente inflamatorio en la imagen en T2.

radiólogo consiga una $\mathrm{RM}$ que muestre más las características en T1 o en T2, de ahí, como ya hemos dicho al inicio de este capítulo, la importancia de determinar qué estamos buscando. Otro aspecto interesante a considerar es que algunos autores determinan relación entre la intensidad de la señal y el grado de dolor (2,34). Incluso se puede mejorar la técnica para los tejidos óseos y los fenómenos de proliferación sinovial, formación de pannus $\mathrm{u}$ otros fenómenos inflamatorios mediante el uso de gadolinio como medio de contraste $(35,36)$.

La identificación del disco puede, no obstante, resultar dificultada si hay variaciones importantes en dicho disco o en el tejido retrodiscal. Por otro lado se encuentra contraindicada en pacientes embarazadas, en portadores de marcapasos, pacientes con grapas vasculares o partículas metálicas en estructuras vitales, así como en individuos con claustrofobia. No está, no obstante, contraindicada si se es portador de aparatos de ortodoncia, implantes o restauraciones dentales $(2,3,10,37)$.

En un principio se consideraba poco útil para valorar tejido óseo en base a que el hueso cortical carece de señal, pero pronto se observó que ese supuesto inconveniente podía ser utilizado para el análisis, llegando a valores mejores que los de la tomografía convencional y escasamente menores que el TC (3). Así pues podríamos determinar que los únicos procesos no detectables son las adherencias y las perforaciones, siendo la artrografía la prueba de elección (2).

\section{INDICACIONES}

Teniendo en cuenta que es el método de elección para el estudio de la anatomía discal, para evaluar todas las formas de desplazamiento de disco y que es de gran valor para determinar los defectos óseos, repasaremos a continuación las diferentes indicaciones reflejadas por Bumann y col. (3):

\section{Reproducción anatómica de las estructuras blandas:}

- Tanto en la anatomía del disco como en su posición se muestra con valores de especificidad y sensibilidad superiores al 90\%. Es también de gran valor para evaluar el tejido retrodiscal, en especial en los cortes paramediales que evitan la interferencia de los aparatos o restauraciones dentales.

- La posición discal en sentido sagital se valora correctamente con tres cortes (medio, central y lateral), tanto en boca cerrada como abierta. Si bien la correlación con cortes anatómicos se acerca al 95\%, existen varios elementos que pueden inducir a error en los cortes sagitales. La existencia de fibrosis en la zona bilaminar con formación de pseudodisco; zonas tendinosas con poca señal del tendón del músculo pterigoideo lateral y finalmente fibrosis de la parte ventral y superior de la cápsula. Una vez más insistiremos en que la imagen obtenida debe coincidir con la impresión clínica, sino es así podremos incluir cortes de exploración adicionales.

- La posición en el plano frontal se determina con la boca cerrada y el corte ideal es el posterior dado que el disco en la zona medial y anterior es excesivamente delgado. Los autores citan un desplazamiento lateral y medial del $1,8 \%$ y $0,9 \%$ respectivamente en el paciente sano, frente a un $4,5 \%$ y un $4,1 \%$ en los pacientes con sintomatología. Es importante a este respecto que una angulación escasa en el corte puede simular un desplazamien- 
to lateral y si es excesiva simular un desplazamiento medial.

- La morfología de la cara posterior de unos 2,6 mm de diámetro puede tener un aspecto biconvexo, biplanar o aplanado en forma de cuña (3). Esta zona es importante para la estabilidad del complejo disco-cóndilo y en casos de fuerzas craneales o dorso-craneales se producirá aplanamiento, pero si la carga es puramente dorsal puede haber desplazamiento sin aplanamiento de dicha zona.

- El análisis de la zona bilaminar y el valor de su adaptación progresiva es de suma utilidad si tenemos en cuenta que el $90 \%$ de los dolores derivan de esta zona. La formación de fibrosis a dicho nivel puede semejar un seudodisco. Esta fibrosis puede aparecer con una posición discal fisiológica o en desplazamiento con o sin recapturación. Ésta zona bilaminar sólo se puede explorar de forma adecuada si analizamos las estructuras con escasa señal tanto en T1 como en T2.

- Las adherencias del disco no siempre provocan limitación de la movilidad. En ocasiones pueden coincidir con una posición fisiológica del mismo. Esto es debido a una hipermovilidad del espacio articular superior que compensa la limitación del inferior. Estas adherencias resultan de difícil diagnóstico en especial si no hay limitación en el desplazamiento discal.

\section{Valoración de la movilidad y desplazamiento del disco}

Para determinar que existe una hipermovilidad del disco se ha de encontrar un desplazamiento anterior del mismo por lo menos en un corte de la articulación (medial, central o lateral). Hablaremos de desplazamiento parcial cuando se encuentre desplazado sólo en alguno de los tres cortes examinados (medial, central o lateral). El $90 \%$ de los casos corresponde a desplazamientos de la zona lateral y el $10 \%$ a la zona medial. Este desplazamiento conlleva siempre cierto grado de distensión de la zona retrodiscal.

Hablaremos de un desplazamiento total cuando la cara posterior del disco esta desplazada en el corte medial, central y lateral. El desplazamiento total del disco se puede encontrar hasta en un $12 \%$ de los pacientes asintomáticos, estos datos pueden llegar hasta el $85 \%$ en pacientes con sintomatología.
Cuando empleamos los términos de recapturación parcial o total también nos estamos refiriendo al concepto tridimensional en sentido medial, central y lateral.

Los desplazamientos posteriores del disco son raros y generalmente debidos a traumatismos. El cóndilo quedara tanto en boca abierta como cerrada ventral con respecto al disco.

\section{Hipermovilidad condilar}

Entendemos por hipermovilidad la rotación del cóndilo por delante del cenit de la eminencia articular. Si el paciente no puede volver a cerrar la boca desde esta posición hablaremos de luxación condilar. En esta situación el disco puede quedar en la zona posterior del cóndilo pero no debe confundirse con un desplazamiento posterior del mismo ya que corresponde a la laxitud de la cápsula y en cierre recuperará su posición fisiológica.

\section{Reproducción anatómica de los tejidos óseos}

El análisis de las alteraciones óseas tiene generalmente poca implicación terapéutica excepto cuando las adaptaciones regresivas comportan dolor o el progreso de las mismas comporta un compromiso en la recapturación futura del disco desplazado. Los estadíos iniciales se diagnostican mejor en T1 y los estadíos más avanzados en T2. De forma genérica podemos decir que la esclerosis es hipodensa en T1 y T2 y que el edema de la médula ósea es hipodenso en T1 e hiperdenso en T2.

Clásicamente se ha considerado la RM una prueba de escaso valor para analizar los cambios óseos, no obstante mediante la realización sistemática de imágenes en T1 y T2 con los modernos aparatos, la resolución es similar a la TC; e incluso se puede mejorar el resultado con diferentes técnicas de contraste (38-40).

- La osteoartrosis (cambios regresivos) afecta preferentemente al cartílago de la superficie articular y al hueso subcondral. Sólo podremos apreciar estos cambios cuando tengan un cierto grado de deterioro, deterioro que podrá acompañarse o no de alteraciones discales y de clínica. 
- Podemos verificar los cambios óseos que se han producido después de las fracturas condilares así como las transformaciones óseas (cambios progresivos) que se puedan producir frente a un estímulo mecánico. Este aspecto puede resultar útil en tratamientos de distracción mandibular y en tratamientos ortodóncico-ortopédicos.

- La necrosis avascular es una necrosis del hueso subcondral y de la médula ósea como consecuencia de una reducción de la vascularización. Puede asociarse a cuerpos libres intraarticulares o no. Este proceso se puede presentar de carácter idiopático o asociado a desplazamientos anteriores del disco, discectomias u ostectomias mandibulares entre otras entidades. En estos casos la señal puede confundirse con el patrón observado en la osteoartrosis y será importante para el diagnóstico la combinación de esclerosis y el contorno intacto de las superficies articulares.

\section{Análisis métrico cuantitativo}

El análisis de la RM permite una interpretación de los parámetros anatómicos de forma fiable pero no nos permite realizar estudios cualitativos de la relación del cóndilo, el disco y la fosa. Existen, no obstante, los análisis métricos con RM, que son equivalentes a los estudios cefalométricos y permiten desarrollar 31 puntos de referencia, determinando 51 variables en total (3). Tiene especial valor en la situación articular antes y después del tratamiento ortodóncico o quirúrgico.

\section{Reproducción tridimensional}

Desde principio de los noventa es posible gracias al software adecuado realizar reconstrucciones tridimensionales a partir de las imágenes de RM. Estos datos pueden utilizarse, igual que comentamos para el TC, mediante máquinas de esterolitografía para confeccionar modelos preoperatorios o de estudio (24).

\section{Estudios de microscopía}

Mediante la utilización de campos magnéticos más potentes que los empleados normalmente en RM se pueden conseguir imágenes de resolución microscópica (unas 25 micras), es la denominada microscopía mediante resonancia magnética y se peuden conseguir imágenes de diferentes capas del cartílago
(41). También existen trabajos mediante la aplicación de iones de $\mathrm{Mn}^{2+}$ o la realización de espectroscopia asociada a RM para el estudio del metabolismo muscular (3).

\section{Futuro}

Para muchos estudiosos la RM es la prueba diagnóstica del futuro. Se realizan trabajos con liposomas que mejoran la imagen de las lesiones cartilaginosas. Los modernos escaners de RM funcionales interactivos permiten reducir los tiempos de exploración. (3). Finalmente las exploraciones dinámicas en tiempo real se están utilizando ya en exploraciones cardiacas y es una técnica en la que se investiga día a día para obtener mejores resultados diagnósticos en todas sus aplicaciones $(42,43)$.

\section{BIBLIOGRAFÍA}

1. Velasco E, Cruz D, Velasco C, Monsalve L, Paz J. Los trastornos temporomandibulares en la práctica odontológica. II. El Diagnóstico. Av Odontoestomatol 2002; 18-4: 211-9.

2. Isberg A. Disfunción de la Articulación Temporormandibular. Artes Médicas Latinoamericanas: Sâo Paulo. 2003. 173-98.

3. Bumann A, Lotzmann U. Atlas de Diagnóstico Funcional y Principios Terapéuticos en Odontología. Barcelona: Masson. 2000. 136-200.

4. Okesson J. Oclusión y afecciones temporromandibulares. Madrid: Mosby / Doyma Libros. 1996. 226-98

5. Bermejo A. Medicina Bucal II. Enfermedades y desórdenes temporormandibulares. Dolor orofacial y manifestaciones orales de enfermedades sistémicas. Madrid: Editorial Síntesis. 1998.

6. Velasco E, Cruz D, Velasco C, Monsalve L, Bullón P. Los trastornos temporomandibulares en la práctica odontológica. I. Clasificación y Etiopateogénia. Av Odontoestomatol 2002; 18; 177-89.

7. The american Academy of Orofacial Pain. Okeson JP (Ed). Orofacial pain. Carol Stream, III: Quintaessence Publishing Co, Inc, 1996. 
8. Truelove El, Sommers EE, Leresche L, Dworkin SF, Von Korff M. Clinical diagnostic criteria for TMD. New classsification permits multiple diagnoses. J Am Dent Assoc 1992; 123: 47-54.

9. Brooks SL, Brand JW, Gibbs SJ, Hiollender L, Lurie AG, Omnell KA, Westesson PL, White SC. Imaging of temporomandibular joint: a position paper of the American Academy of Oral and Maxillofacial Radiology. Oral Surg Oral Med Oral Pathol Oral Radiol and Endod 1997; 83:609-18.

10. White S, Pharoah M. Radiología Oral. Principios e interpretación. Madrid: Ediciones Harcourt. 2002. 493-528.

11. Dula K, Sanderink G, van der Stelt PF, Mini R, Buser D. Effects of dose reduction on the detectability of standardized radiolucent lesions in digital panoramic radiography. Oral Surg Oral Med Oral Pathol Oral Radiol and Endod 1998; 86: 227-33.

12. Ludlow JB, Davies KL, Tyndall DA. Temporomandibular joint imaging: a comparative study of diagnostic accuracy for the detection of bone changee with biplanar multidirectional tomography and panoramic images. Oral Surg Oral Med Oral Pathol Oral Radiol and Endod 1995; 80: 735-43.

13. Habets LL, Bezuur JN, Neiji M, Hansson TL. The orthopantomogram, an aid in diagnosis of temporomandibular joint problems. II. The vertical symmtry. J Oral Rehabil 1988; 15: 465-71.

14. Kjellberg $\mathrm{H}$, Condylar height on panoramic radiograhas. A methodologic study with a clinical application. Acta Odontol Scand 1994; 52: 43-50.

15. Pasler FA. Radiología odontológica. Barcelona: Salvat. 1988.

16. Avrahamy E, Katz R. An association between imaging and acute postraumatic ear bleeding with trismus. Oral Surg Oral Med Oral Pathol Oral Radiol and Endod 1998; 85: 244-7.

17. Eliasson S, Isacsson G. Radiographic signs of temporaomandibular disorders to predict outcome of treatment. J Craniomandib Disord 1992; 6: 281-7.

18. Callender KI, Brooks SL. Usefulness of tomography in the evaluation of patients with tempo- romandibular disorders: a retrospective clinical study. Oral Surg Oral Med Oral Pathol Oral Radiol and Endod 1996; 81: 710-9.

19. Hönig JF, Merten HA, Korth OE, Halling F. Coronoid process enlargment. Dentomaxillofaci Radiol 1994; 52: 214-8.

20. Avrahami E, Frishman E, Weiss-Perezt J, Horowitz I. Computed Tomography of healing condylar fractures with some clinical correlations. Clin Radiol 1993; 47: 269-73.

21. Choi BH. Magnetic resonance imaging of the tenmporomandibular joint after functional treatment of bilateral condylar fractures in adults Int $\mathrm{J}$ Oral Maxilofac Surg 1997; 26: 344-7.

22. Oezmen Y, Mischkowski RA, Lenzen J, Fischbach R. MRI examination of the TMJ and functional results after conservative and surgical treatment of mandibular condyle fractures. Int $\mathrm{J}$ Oral Maxillofac Surg 1998; 27: 33-7.

23. Kermer C, Lindner A, Friede I, Wagner A, Millesi W. Preoperative stereolithographic model planning for primary reconstruction in craniomaxillofacial trauma surgery. J Cracniomaxillofac Surg 1998; 26: 136-9.

24. Sailer HF, Haers PE, Zollikofer CP, Warnike T, Carls FR, Stucki P. The value os stereolithographic models for preoperative diagnosis of craniofacial deformities and planning of surgical corrections. Int J Oral Maxillofac Surg 1998; 27: 327-33.

25. Disponible en URL: http://www.medicalmedilling.com. Accedido 8 de febrero de 2004.

26. Undt G, Wild K, Reuther G, Ewers R. MRI-based stereolithographic moels of the temporomandibular joint: technical innovation. J Maxillofac Surg 2000; 28: 258-63.

27. Westesson PL, Eriksson L, Kurita K. Realiability of negative clinical temporomandibular joint examination: prevalence of disk desplacement in asymptomatic temporomandibular joints. Oral Surg Oral Med Oral Pathol 1989; 68: 551-4.

28. Salazar C, González J, García A. Protocolo de artroscopia diagn'sotica de la articulación termporomandibular. Rev Esp Cir Oral Maxillofac 1992; 14: 193-8. 
29. Ohnuki T, Foukuda M, Lino M, Takahashi T. Magnetic resonance evaluation of the disk before and after arthroscopic surgery for temporomandibular joint disorders. Oral Surg Oral Med Oral Pathol Oral Radiol Endod 2003; 96: 141-8

30. Yura S, Totsuka Y, Yohikawa T, Inoue N. Can arthocentesis relase intracapsular adhesions? Athroscopy finding before and after irrigation under sufficcient hydraulic pressure. J Oral Maxillofac Surg 2003; 61: 1253-6

31. Cascone P, Leonardi R, Marino S, Carnemolla ME. Intracapsular fractures of mandibular condyle: diagnosis, treatment, and anatomical and pathological evaluations. J Craniofac Surg 2003; 14: 184-91.

32. Emshoff R, Brandlmaier I, Bertram S, Rudisch A. Comparación de dos métodos para el diagnóstico de luxación del disco articular temporomandibular sin reducción. JADA 2002; 5: 32-41.

33. Ren YF, Westesson PL, Isberg A. Magnetic resonance imaging of the temporomandibular joint. Value of pseudodynamic images. Oral Surg Oral Med Oral Pathol Oral Radiol Endod 1996; 81: 110-23.

34. Sano T, Westesson PL. Magnetic resonance imaging of the temporomandibular joint. Increased T2 signal in the retrodiscal tissue of painful joints. Oral Surg Oral Med Oral Pathol Oral Radiol Endod 1995; 79: 511-6.

35. Matsumura Y, Nomura J, Murata T, Inui M, Nagai K, Yanae S, Nomura Y, Tagawa T. Magnetic resonance imaging of synovial proliferation in temporomandibular disordes with pain. J. Comput Assist Tomogr 2004; 28: 73-9.

36. Ogasawara T, Kitagawa Y, Ogawa T, Yamada T, Kawamura Y, Sano K. Inflammatory change in the upper joint space in temporomandibular joint with internal derangement on gadolinium-enhanced MR imaging. Int J Oral Maxillofac Surg 2002; 31: 252-6.

37. Tetsumura A, Honda E, Sasaki T Kino K. Metallic residues as a source of artifacts in magnetic resonance imaging of the temporomandibular joint. Dentomaxilofacial Radiology 1999; 28: 186-190.
38. Uhl M, Allmann KH, Tauer U, Laubenberger J, Adler CP, Ihling Ch, Langer M. Comparison of RM sequences in quintifiying in vitro cartilage degeneration in osteoarthitis of the knee. The British Journal of Radiology 1998; 71: 291-6.

39. Uhl M, Ihling C, Allmann KH, Laubenberger J, Tauer U, Adler CP, Langer M. Human articular cartilage: in vitro correlation of MRI and histologic findings. Wur Radiol 1998; 8: 1123-9.

40. Wagner $M$, Werner A, Grunder W. Visualization of collanase-induced cartilage degration using NMR mycroscopy. Invest Radiol 1999; 34:607-14.

41. Koizuka I, Furman JM, Mendoza JC. Plasticity of responses to off-vertical axis rotation. Acta Otolaryngol 1997; 117: 321-4.

42. Güler N, Yatmaz PI, Ataoglu H, Emilik D, UCAN S. Temporomandibular internal derangement correlation of MRI findings with clinical symptoms of pain and joint sounds in patients with bruxing behaviour. Dentomaxillofacial Radiology 2003; 32: 304-10

43. Shellock FG. Functional assessment of the joints kinematic magnetic resonance imaging. Semn Musculoskelet Radiol 2003; 7: 249-76.

\section{CORRESPONDENCIA}

José López López

c/ Marina, 291, sobreático

08025 Barcelona

Tel.: 933859346

Fax: 933859346

E-mail: 18575jll@comb.es

jl.lopez@ub.edu 